\title{
Oxytocin Enhances Cranial Visceral Afferent Synaptic Transmission to the Solitary Tract Nucleus
}

\author{
James H. Peters, ${ }^{1}$ Stuart J. McDougall, ${ }^{1}$ Daniel 0. Kellett, ${ }^{2}$ David Jordan, ${ }^{\dagger}{ }^{\dagger}$ Ida J. Llewellyn-Smith,,${ }^{3}$ and \\ Michael C. Andresen ${ }^{1}$ \\ ${ }^{1}$ Department of Physiology and Pharmacology, Oregon Health \& Science University, Portland, Oregon 97239-3098, ${ }^{2}$ Department of Physiology, Royal Free \\ and University College Medical School, University College London, London WC1E 6BT, United Kingdom, and ${ }^{3}$ Cardiovascular Medicine and Centre for \\ Neuroscience, Flinders University, Bedford Park, South Australia 5042, Australia
}

Cranial visceral afferents travel via the solitary tract (ST) to contact neurons within the ST nucleus (NTS) and activate homeostatic reflexes. Hypothalamic projections from the paraventricular nucleus (PVN) release oxytocin (OT) to modulate visceral afferent communication with NTS neurons. However, the cellular mechanisms through which OT acts are poorly understood. Here, we electrophysiologically identified second-order NTS neurons in horizontal brainstem slices by their low-jitter, ST-evoked glutamatergic EPSCs. OT increased the frequency of miniature EPSCs in half of the NTS second-order neurons (13/24) but did not alter event kinetics or amplitudes. These actions were blocked by a selective OT receptor antagonist. OT increased the amplitude of ST-evoked EPSCs with no effect on event kinetics. Variance-mean analysis of ST-evoked EPSCs indicated OT selectively increased the release probability of glutamate from the ST afferent terminals. In OT-sensitive neurons, OT evoked an inward holding current and increased input resistance. The OT-sensitive current reversed at the $\mathrm{K}^{+}$equilibrium potential. In in vivo studies, NTS neurons excited by vagal cardiopulmonary afferents were juxtacellularly labeled with Neurobiotin and sections were stained to show filled neurons and OT-immunoreactive axons. Half of these physiologically characterized neurons (5/10) showed close appositions by OT fibers consistent with synaptic contacts. Electron microscopy of medial NTS found immunoreactive OT within synaptic boutons. Together, these findings suggest that OT released from PVN axons acts on a subset of second-order neurons within medial NTS to enhance visceral afferent transmission via presynaptic and postsynaptic mechanisms.

Key words: autonomic; brainstem; synaptic; vagal afferents; immunocytochemistry; ultrastructure

\section{Introduction}

Descending projections from the paraventricular nucleus (PVN) of the hypothalamus influence medullary reflexes through the release of neuropeptides (White et al., 1984). One prominent site modulated by PVN input is the nucleus of the solitary tract (NTS) (Sawchenko and Swanson, 1982; Barberis and Tribollet, 1996). PVN fibers containing the neuropeptide oxytocin (OT) are distributed throughout the brain and brainstem areas, including the nucleus of the solitary tract (NTS) (Sofroniew and Schrell, 1980; Maley, 1996; Blevins et al., 2003). Microinjection of OT into NTS enhances visceral afferent-evoked activity, including cardiovas-

\footnotetext{
Received July 21, 2008; revised Sept. 29, 2008; accepted 0ct. 5, 2008.

This work was supported by National Institutes of Health Grant HL-58760 (M.C.A.) and Fellowship HL-88894 (J.H.P.); National Health and Medical Research Council of Australia Overseas Training C. J. Martin Fellowship \#400405 (S.J.M.), Project Grant 229907 (I.J.L.-S.), and Principal Research Fellowship 229921 (I.J.L.-S.); a Biomedical Research Collaboration grant from the Wellcome Trust UK, 067996/Z/02/Z (D.J. and I.J.L.-S.); and the British Heart Foundation (D.J., D.0.K.). We thank Carolyn Martin, Natalie Fenwick, and Lee Travis for invaluable technical assistance. We would like to specifically acknowledge the efforts of Prof. Dave Jordan, who passed away before the publication of this work.

${ }^{\dagger}$ Deceased June 30, 2007.

Correspondence should be addressed to Dr. James H. Peters, Department of Physiology and Pharmacology, L334, Oregon Health \& Science University, 3181 SW Sam Jackson Park Road, Portland, OR 97239-3098. E-mail: petersj.ohsu@gmail.com.

DOl:10.1523/JNEUROSCI.3419-08.2008

Copyright $\odot 2008$ Society for Neuroscience $\quad 0270-6474 / 08 / 2811731-10 \$ 15.00 / 0$
}

cular (Michelini, 2007) and gastrointestinal reflexes (Flanagan et al., 1992). In vivo electrical stimulation of the PVN releases OT within the NTS (Landgraf et al., 1990) and local delivery of OT excites individual extracellularly recorded NTS neurons (Henry and Sessle, 1989; Raggenbass et al., 1989; McCann and Rogers, 1990). Selective OT receptor antagonists inhibit OT-sensitive reflexes, consistent with endogenous oxytocinergic tone in the NTS (Flanagan et al., 1992; Michelini, 2007).

Cranial visceral afferents in the solitary tract (ST) synapse centrally onto neurons within the NTS and are the first step in homeostatic reflex pathways (Andresen and Kunze, 1994; Saper, 2002). ST-NTS neurotransmission maintains a characteristically high probability of glutamate release (Bailey et al., 2006), which provides an intrinsically high safety factor for transmission (Doyle and Andresen, 2001). Functional groups of second-order NTS neurons show a loose viscerotopic distribution that reflects the distribution of ST afferent fibers (Loewy, 1990; Andresen and Kunze, 1994). Thus, the ability of OT to modulate reflex function will depend on the specific distribution of OT and its receptor. Despite clear functional evidence for OT receptors within the NTS, the cellular actions of OT remain to be characterized. In the spinal cord, OT facilitates glutamatergic neurotransmission via a presynaptic mechanism (Breton et al., 2008), whereas OT produces postsynaptic depolarization of neurons within the dorsal 
motor nucleus of the vagus (DMV) (Raggenbass et al., 1987; Dubois-Dauphin et al., 1992). The ability of OT to modulate ST-NTS neurotransmission may occur presynaptically at the afferent terminal or postsynaptically on NTS neurons.

We hypothesized that OT would enhance ST afferent to NTS neurotransmission. Second-order NTS neurons in horizontal brainstem slices were identified by the characteristic EPSCs evoked from ST stimulation (Doyle and Andresen, 2001). We found that OT increased the frequency of miniature EPSCs (mEPSCs) in half of the NTS neurons tested, an effect attenuated by an OT specific receptor antagonist. Variance-mean $(V-M)$ analysis of STevoked EPSCs (ST-EPSCs) confirmed a selective presynaptic effect of OT to increase the probability of glutamate release. In addition, OT reduced a tonically active potassium conductance; indicating coordinated presynaptic and postsynaptic mechanisms in these neurons. Last, in intact rats, we identified and juxtacellularly labeled NTS neurons that were activated by vagal cardiopulmonary afferents and found that half received close appositions from OT-immunoreactive terminals. Together, these findings indicate OT selectively enhances cranial visceral afferent transmission to a subpopulation of medial NTS neurons via distinct presynaptic and postsynaptic mechanisms.

\section{Materials and Methods}

Animals. All animal procedures were performed with the approval of the respective institutions; including the Institutional Animal Care and Use Committees at Oregon Health \& Science University (Portland, OR), the Animal Welfare Committee of Flinders University, and under a U.K. Home Office License in accordance with the regulations of the U.K. Animals (Scientific Procedures) Act, 1986. In all experiments adult male Sprague Dawley rats $(>160 \mathrm{~g})$ were used. Animals were housed under $12 \mathrm{~h}$ light/ $12 \mathrm{~h}$ dark conditions and fed standard pellet chow ad libitum.

In vitro electrophysiology: horizontal brainstem slices. Brainstem slices were prepared from isoflurane anesthetized rats as previously described (Doyle et al., 2004). Briefly, the medulla was removed and placed in cooled artificial CSF (aCSF) containing (in $\mathrm{mm}$ ): $125 \mathrm{NaCl}, 3 \mathrm{KCl}, 1.2$ $\mathrm{KH}_{2} \mathrm{PO}_{4}, 1.2 \mathrm{MgSO}_{4}, 25 \mathrm{NaHCO}_{3}, 10$ dextrose, and $2 \mathrm{CaCl}_{2}$, bubbled with $95 \% \mathrm{O}_{2}-5 \% \mathrm{CO}_{2}$. The brain was trimmed to yield a tissue block centered on obex. A wedge of tissue was removed from the ventral surface so that a horizontal cut yielded a single 250 - $\mu \mathrm{m}$-thick slice that contained the ST together with NTS neuronal cell bodies. Slices were cut with a sapphire knife (Delaware Diamond Knives) mounted in a vibrating microtome (VT1000S; Leica Microsystems). Slices were secured in a custom perfusion chamber with a fine polyethylene mesh (Siskiyou Design Instruments) and perfused with aCSF (300 mOsm) constantly bubbled with $95 \% \mathrm{O}_{2} 5 \% \mathrm{CO}_{2}$ at $34-35^{\circ} \mathrm{C}$.

In vitro whole-cell patch recordings. The anatomical landmarks preserved in the horizontal slices allowed targeting of neurons within the medial subnucleus of the caudal NTS (Fig. 1). Recorded neurons were located medial to the ST and within $250 \mu \mathrm{m}$ rostral or caudal of obex
(Fig. 1). Patch electrodes were visually guided to neurons using infrared illumination and differential interference contrast optics (DIC) $(40 \times$ water-immersion lens) on an Axioskop 2 microscope (Zeiss) with digital camera (Hamamatsu Photonic Systems). Recording electrodes (2.8-3.5 $\mathrm{M} \Omega)$ were filled with a low- $\mathrm{Cl}^{-}\left(10 \mathrm{mM}, E_{\mathrm{Cl}}=-69 \mathrm{mV}\right)$ intracellular solution containing (in $\mathrm{mm}$ ): $6 \mathrm{NaCl}, 4 \mathrm{NaOH}, 130 \mathrm{~K}$-gluconate, 11 EGTA, $1 \mathrm{CaCl}_{2}, 1 \mathrm{MgCl}_{2}, 10$ HEPES, $2 \mathrm{Na}_{2} \mathrm{ATP}$, and $0.2 \mathrm{Na}_{2} \mathrm{GTP}$. The intracellular solution was pH 7.3 and 296 mOsm. Neurons were studied under voltage clamp conditions with an Axopatch 200A or MultiClamp 700B amplifier (Molecular Devices) and held at $V_{\mathrm{H}}=-60 \mathrm{mV}$ using pipettes in open, whole-cell patch configuration. Signals were filtered at $10 \mathrm{kHz}$ and sampled at $30 \mathrm{kHz}$ using p-Clamp software (version 8.2, Molecular Devices).

In vitro identification of second-order neurons. A concentric bipolar stimulating electrode ( $200 \mu \mathrm{m}$ outer tip diameter; Frederick Haer) was placed on distal portions of the visible ST rostral to the recording region (Fig. 1). This remote placement of the stimulating electrode $(1-3 \mathrm{~mm}$ from recorded neurons) minimized the likelihood of activation of non-ST axons or local neurons. Current shocks were delivered to ST every $3 \mathrm{~s}$ (shock duration $0.1 \mu \mathrm{s}$ ) using a Master-8 isolated programmable stimulator (A.M.P.I.). In some tests, responses to bursts of five shocks (20 ms intershock interval) assessed frequency dependent amplitude depression and synaptic failures for ST-EPSCs. Latency was measured as the time between the ST shock and the onset of the resulting EPSC. 
Synaptic jitter was calculated as the SD of ST-EPSC latencies for 30-40 trials within each neuron. Jitters of $<200 \mu$ s reliably identify direct, monosynaptic afferent inputs (Doyle and Andresen, 2001).

Isolation of miniature EPSCs. In second-order NTS neurons identified by their ST-EPSC response jitter, miniature EPSCs (mEPSCs) were isolated by adding gabazine (GZ: SR95531; $3 \mu \mathrm{M}$ ) to block synaptic $\mathrm{GABA}_{\mathrm{A}}$ receptors and tetrodotoxin (TTX; $3 \mu \mathrm{M}$ ) to the aCSF bath perfusion. All drugs were purchased from Tocris unless otherwise noted. OT and the OT receptor antagonist $\left(\left[\mathrm{D}\left(\mathrm{CH}_{2}\right)_{5}{ }^{1}, \mathrm{Tyr}(\mathrm{Me})^{2}, \mathrm{Thr}^{4}, \mathrm{Orn}^{8}\right.\right.$, des-Gly$\mathrm{NH}_{2}{ }^{9}$ ]-vasotocin) were purchased from Bachem Bioscience. The nonNMDA receptor blocker 1,2,3,4-tetrahydro-6-nitro-2, 3-dioxo-benzo quinoxaline-7-sulfonamide (NBQX) was obtained from Sigma-RBI.

Variance-mean analysis. $V-M$ analysis of ST-EPSCs was performed as previously described (Bailey et al., 2006). Briefly, the release probability $\left(P_{\mathrm{R}}\right)$, number of functional release sites $(N)$, and quantal size $(q)$ were estimated by determining the dependence of EPSC variance $(V)$ on mean amplitude $(M)$ in various external bath $\mathrm{Ca}^{2+}$ concentrations that alter the probability of synaptic release (Silver et al., 1998; Clements, 2003). The relationship between $V$ and $M$ can be described by the equation: $V=$ $q M-M^{2} / N$. We constructed $V-M$ relationships from tests of steadystate ST-EPSCs in varied concentrations of extracellular $\mathrm{Ca}^{2+}$ using equimolar aCSF substitution of $\mathrm{Ca}^{2+}$ with $\mathrm{Mg}^{2+}$. EPSC amplitudes were measured as the peak current minus the mean baseline current immediately preceding each stimulus shock (averaged over $100 \mathrm{~ms}$ ). $V$ was calculated as the square of SD of $\geq 50$ successive ST-EPSCs amplitudes in each condition. For each neuron, measured $V$ and $M$ were determined in different calcium conditions ( $\left.2 \mathrm{mM}, 1 \mathrm{~mm}, 0.25 \mathrm{mM} \mathrm{Ca}^{2+}\right)$ and fits were constrained to intersect the zero release state $(V=0$ at $M=0)$. The data were plotted and fit using a least-squares method with the following equation for a parabolic model: $y=K_{1} x+K_{2} x^{2}$, where $y$ is the variance in EPSC amplitude, $x$ is the mean amplitude, $K_{1}$ equals $q$, and $1 / K_{2}$ represents $N$ (Origin version 7.5, OriginLab). All relationships closely followed parabolic regression fits. Using the measured mean EPSC amplitude and variance, we estimated the maximal EPSC amplitude $\left(\right.$ EPSC $\left._{\max }\right)$, and this was used to normalize aggregate data across neurons. During OT experiments (aCSF $\left.\left[\mathrm{Ca}^{2+}\right]=1 \mathrm{~mm}\right), M$ and $V$ changes during treatments were calculated from ST-EPSCs recorded within a 2-3 min period centered on peak responses.

Statistical analysis of in vitro synaptic responses. Digitized waveforms were analyzed using an event detection and analysis program (MiniAnalysis, Synaptosoft) for all miniature synaptic currents and Clampfit 10 (Molecular Devices) for all ST-stimulated currents. To obtain accurate decay-time constants, amplitude and baseline values for miniature synaptic currents, those events smaller then $10 \mathrm{pA}$ and those with multiple peaks were excluded. All events $>10 \mathrm{pA}$ were counted for frequency values. Decay-time constants were acquired by fitting a single exponential between the $10 \%$ and $90 \%$ peak amplitude portion of the current decay. For statistical comparisons repeated-measures ANOVA, one-way ANOVA, Fisher's PLSD post hoc analysis, and Kolmogorov-Smirnov $(\mathrm{K}-\mathrm{S})$ test, were used when appropriate. Analysis of mEPSCs frequency and waveform parameters (decay-time constant and amplitude) were averaged across each group ( 5 min bins) and compared by Friedman ANOVA on ranks or a one-way ANOVA each with post hoc testing against control (SigmaStat). All data are represented as mean \pm SEM with $p<0.05$ considered statistically significant.

In vivo identification of vagal responsive NTS neurons and juxtacellular labeling. To examine the association of OT-containing axons and NTS neurons physiologically activated by vagal afferents, we identified individual cardiopulmonary NTS neurons in situ using established pharmacological and electrical stimulation protocols and then labeled them for anatomical studies as previously described (Jones et al., 2002; Jeggo et al., 2005). Rats $(250-450 \mathrm{~g}, n=6)$ were anesthetized with sodium pentobarbitone $(60 \mathrm{mg} / \mathrm{kg}$, i.p. $)$ and artificially ventilated. Gallamine $(8 \mathrm{mg} / \mathrm{kg}$, i.v.) or $\alpha$-bungarotoxin ( $150 \mu \mathrm{g} / \mathrm{kg}$, i.v.) were given for neuromuscular blockade. The level of anesthesia was monitored and maintained until perfusion (Jones et al., 2002). Animals were secured in the stereotaxic frame and a dorsolateral approach was used to expose the cervical vagosympathetic trunk in the neck. The vagus was dissected, placed on a bipolar silver wire electrode and fixed in position with paraffin wax or dental impression material (President light body dental polyvinylsiloxane; Coltene). Extracellular single-unit activity of the NTS neurons was obtained using glass electrodes filled with $1.5-2.5 \%$ Neurobiotin $(\mathrm{N}-(2$ aminoethyl) biotinamide hydrochloride; Vector Laboratories) in 0.5-1.0 $\mathrm{M} \mathrm{NaCl}$ (resistance 5-30 M $\Omega$ ) and an Axoclamp 2A amplifier (Molecular Devices). NTS neurons receiving vagal input were identified by electrical stimulation (5-500 $\mu \mathrm{A}, 1 \mathrm{~ms}, 0.6-1 \mathrm{~Hz}$ ) of the vagus (isolated programmable stimulator DS2A and 4030; Digitimer). Neuronal discharge activated by infusion of phenylbiguanide $(0.05 \mathrm{mg} / \mathrm{ml}$ in $0.9 \% \mathrm{NaCl})$ into the right atrium indicated cardiopulmonary afferent input (Kay and Armstrong, 1990). NTS neurons responsive to vagal and cardiopulmonary afferent stimulation had consistent response latencies. These vagal afferent responsive neurons were filled with Neurobiotin by injection of positive current pulses (200 $\mathrm{ms}, 50 \%$ duty cycle, 2-10 min) delivered through the recording electrode at sufficient amplitude to entrain the cell to fire with the positive current $(0.1-10 \mathrm{nA})$. Rats were perfused $1-2 \mathrm{~h}$ after the last neuron was filled. Sections containing the recorded neurons were processed for OT immunohistochemistry (see below) and examined for OT-immunoreactive terminals contacting the physiologically identified NTS neurons. Close appositions by OT-positive terminals onto filled neurons were identified with a $100 \times$ oil-immersion lens if (1) no space could be discerned between the terminal and the neuron for terminals lying side-by-side with a filled neurons or (2) the terminal and the filled neuron were in the same focal plane for terminals overlying filled neurons. All sections through each filled neuron were examined.

OT immunohistochemistry. Under deep anesthesia (sodium pentobarbitone $100 \mathrm{mg} / \mathrm{kg}$, i.p.), animals were administered heparin (1000 IU) and perfused transcardially with DMEM/F12 tissue culture medium (D8900; Sigma) followed by $4 \%$ formaldehyde in $0.1 \mathrm{~m}$ phosphate buffer, $\mathrm{pH}$ 7.4. Animals with Neurobiotin filled neurons were perfused with heparinized physiological saline followed by $4 \%$ formaldehyde in $0.1 \mathrm{M}$ phosphate buffer, pH 7.4. For light microscopy (LM) brains were postfixed for $3 \mathrm{~d}$ at room temperature, saturated with sucrose, and sectioned transversely at $30 \mu \mathrm{M}$. Animals for electron microscopy (EM) were perfused with $4 \%$ formaldehyde plus $0.3 \%$ glutaraldehyde (Electron Microscopy Sciences) in $0.1 \mathrm{~m}$ phosphate buffer, $\mathrm{pH}$ 7.4. Brains were postfixed for $2 \mathrm{~h}$ in the same fixative, washed in phosphate buffer and stored overnight at $4^{\circ} \mathrm{C}$. Sections for EM were cut transversely at $50 \mu \mathrm{m}$.

Light microscopy and Neurobiotin visualization. Sections for LM were permeabilized by $3 \times 10 \mathrm{~min}$ washes in $0.3 \%$ Triton X-100 in $10 \mathrm{~mm}$ Tris, $0.9 \% \mathrm{NaCl}, 0.05 \%$ thimerosal in $10 \mathrm{~mm}$ phosphate buffer, $\mathrm{pH} 7.4$ (TPBS) followed by $10 \%$ normal horse serum (NHS) in TPBS-Triton for at least $30 \mathrm{~min}$. The sections were incubated in 1:250,000 guinea-pig anti-OT (Peninsula Laboratories, Bachem AG) in TPBS-Triton-10\% NHS for $3 \mathrm{~d}$, 1:500 biotinylated donkey anti-guinea-pig Ig (Jackson ImmunoResearch Laboratories) in TPBS-Triton-1\% NHS overnight, and finally in 1:1500 ExtrAvidin-horseradish peroxidase (E-2886, Sigma) in TPBS-Triton for 4-6 h. After each exposure, sections were washed $3 \times 10 \mathrm{~min}$ in TPBS. OT-immunoreactive axons were visualized with a nickel-intensified diaminobenzidine $(\mathrm{DAB})$ reaction in which peroxide was generated by glucose oxidase (Llewellyn-Smith et al., 2005). Sections containing Neurobiotin-filled neurons were processed as previously described (Jones et al., 2002). To block endogenous peroxidase activity tissue was exposed to $1 \%$ hydrogen peroxide in distilled water for $20 \mathrm{~min}$ before treatment with TPBS-Triton and NHS. The sections were incubated for 2-3 d in 1:250 ExtrAvidin-horseradish peroxidase (Sigma) plus guineapig anti-OT antisera (see above) in 10\% NHS-TPBS-Triton. Filled neurons were visualized with an imidazole-intensified $\mathrm{DAB}$ reaction (Llewellyn-Smith et al., 2005). After washes, OT-immunoreactive axons were then visualized as described above. Sections were mounted on subbed slides, dehydrated and coverslipped with Permaslip (Newcomer Supply). Digital images from sections examined by LM were captured with an Olympus BH2 microscope and a SPOT RT color camera using SPOT RT software v3.0 (Diagnostic Instruments).

Electron microscopy. Sections from rats perfused for EM were washed for $3 \mathrm{~h}$ in $50 \%$ ethanol (with distilled water) to improve antibody penetration (Llewellyn-Smith and Minson, 1992) and then exposed to $10 \%$ normal NHS in TPBS without Triton for at least $30 \mathrm{~min}$. OT immunoreactivity was detected as described above. Stained sections were washed 
in phosphate buffer and osmicated. Sections were then treated with aqueous uranyl acetate and dehydrated in graded acetone solutions followed by propylene oxide. Next, sections were infiltrated with Durcupan (Fluka/Sigma-Aldrich), flat-embedded on slides and polymerized. Areas of NTS were cut out of the resin-embedded sections, reembedded on flat blank blocks, and repolymerized. Ultrathin sections were cut with a diamond knife, mounted on copper mesh grids, and stained with Reynold's lead citrate. Ultrathin sections were photographed with a JEOL 1200EX electron microscope and EM negatives were scanned with a ScanJet $6100 \mathrm{C} / \mathrm{T}$ scanner at 1200 pixels/inch (Hewlett-Packard). Synapses formed by OT-immunoreactive axons were identified by presynaptic vesicle clustering and the presence of a membrane specialization postsynaptically.

\section{Results}

OT increases mEPSC frequency in second-order NTS neurons After identification of second-order NTS neurons (Fig. 1), mEPSCs were isolated with TTX + GZ (Fig. 2). Application of OT rapidly and reversibly increased the frequency of mEPSCs in 13 of 24 second-order NTS neurons (Fig. $2 A, B$ ). OT significantly shifted the cumulative distribution of events $(\mathrm{K}-\mathrm{S}, p<0.001)$ to shorter interevent intervals (Fig. 2C). Across neurons, OT increased the mEPSC frequency by nearly twofold at the highest concentration (1000 nM, $192 \pm 18 \%, n=6)$ (Fig. 2D). The sigmoidal fit of the OT concentration relationship for mEPSC frequency estimated the $\mathrm{EC}_{50}$ at $\sim 70 \mathrm{~nm}$. Even at the highest concentrations, OT failed to alter the amplitudes $(\mathrm{K}-\mathrm{S}, p>0.05)$ (Fig. 3A, left panel) or event kinetics (Fig. 3A, right panel) of the mEPSC. Across OT-sensitive neurons, neither the amplitude (Fig. $3 B$, left panel) or decay phase (Fig. $3 B$, right panel) of averaged events were altered by OT. In some experiments $(n=4$, results not shown), addition of NBQX $(20 \mu \mathrm{M})$ blocked all mEPSCs, indicating their dependence on non-NMDA glutamate receptors. At OT-sensitive, second-order NTS neurons, OT selectively increased the release of glutamate from ST terminals, a presynaptic action that occurred without altering postsynaptic properties (amplitudes or kinetics) of these non-NMDA mediated events. Thus, approximately half of second-order neurons in the medial subnucleus of NTS were OT-sensitive and were intermixed with the remainder of tested second-order neurons that were OT-resistant (Fig. 1). OT-sensitive and OT-resistant neurons had similar intrinsic membrane properties (capacitance: $20.1 \pm 2.4 \mathrm{pF}$ vs $15.1 \pm 2.4 \mathrm{pF}, n=16$, and OT-resistant, $n=13$; and resting membrane potential: $-54.3 \pm 4.7 \mathrm{mV}$ vs $-58.3 \pm 2.2$ $\mathrm{mV} ; p>0.05, t$ tests, OT-sensitive, $n=4$, and OT-resistant, $n=4)$.

The specificity of OT actions was tested by pretreatment of neurons with the competitive OT receptor antagonist $\left(\left[\mathrm{D}\left(\mathrm{CH}_{2}\right)_{5}{ }^{1}, \mathrm{Tyr}(\mathrm{Me})^{2}, \mathrm{Thr}^{4}, \mathrm{Orn}^{8}{ }^{8}\right.\right.$,des-Gly- $\left.\mathrm{NH}_{2}{ }^{9}\right]$-vasotocin, 10 $\mu \mathrm{M})$ (Fig. 4). OT (100 nM) triggered an increase in mEPSC frequency that was reversed by wash in control aCSF (Fig. 4). Addition of the OT receptor antagonist blocked the actions of a second OT exposure in this neuron (Fig. $4 A, B)$. Across neurons $(n=4)$, the frequency effect of OT was attenuated by a 100 -fold excess of antagonist and was no longer significantly different from control $(p>0.05)$ (Fig. 4C). In addition, nearly half (11 of 24$)$ of the second-order NTS neurons tested were OT-resistant $(p>0.05$, ANOVA). Together, these findings suggest that presynaptic OT receptors exist on glutamate terminals contacting a subpopulation of second-order NTS neurons. To test directly whether ST afferent transmission is OT-sensitive, we recorded ST-evoked EPSCs and assessed the release properties of the ST-NTS synapse using $V-M$ analysis.
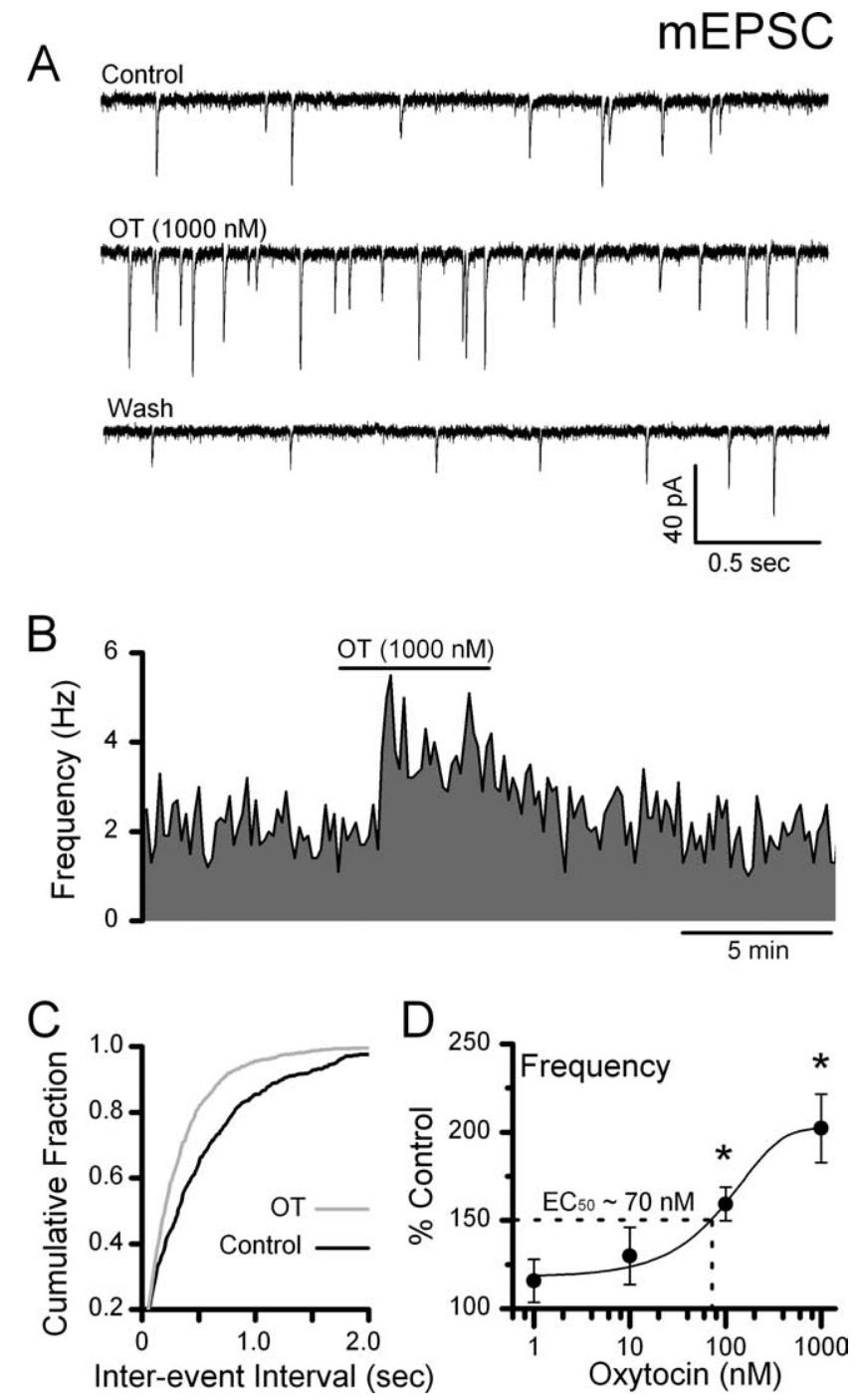

Figure 2. OT selectively increases the frequency of mEPSCS. $\boldsymbol{A}$, Representative current traces in TTX and GZ show that OT (1000 nm) increased the mEPSC frequency in an identified secondorder medial NTS neuron (ST-EPSC latency $=7.70 \mathrm{~ms}$ with jitter $=163 \mu \mathrm{s}$ ). $\boldsymbol{B}$, The frequency histogram of this OT-sensitive neuron demonstrates that increases in frequency occurred rapidly and were reversible after wash (bins $10 \mathrm{~s}$ ). C, OT (gray) significantly shifted cumulative $m E P S C$ frequencies to shorter interevent intervals (K-S test, $p<0.001$ ). $D$, Normalized group averages for similarly tested OT-sensitive NTS neurons show that OT significantly increased mEPSC frequency beginning at $100 \mathrm{~nm}\left(n=4-8\right.$ neurons/conc., ${ }^{*} p<0.05$, ANOVA). These results are consistent with $0 \mathrm{~T}$ acting presynaptically to increase glutamate release onto OTsensitive second-order NTS neurons.

\section{OT selectively increases the ST-EPSC release probability}

Stimulation of the ST evokes time-invariant, large-amplitude EPSCs in second-order NTS neurons (Fig. 5A, left panel) (Doyle and Andresen, 2001). To better understand the site of OT action, we tested the release properties of ST-NTS synapses on secondorder NTS neurons using $V-M$ analysis. Synaptic properties, including $P_{\mathrm{R}}, N$, and $q$, can be estimated based on the relationship between mean EPSC amplitude $(M)$ and its variability $(V)$ under conditions that alter the probability of transmitter release (Clements and Silver, 2000). Reducing the extracellular bath $\mathrm{Ca}^{2+}$ concentration from 2 to $1 \mathrm{mM}$ decreased the mean EPSC amplitude and increased the variability of the peak amplitudes (Fig. $5 \mathrm{~A}$, left panel). However, further reductions to $0.25 \mathrm{mM} \mathrm{Ca}^{2+}$ decreased both the mean ST-EPSC amplitude and its variability (Fig. 5A, left panel). Within each condition, the trial-to-trial variation in 

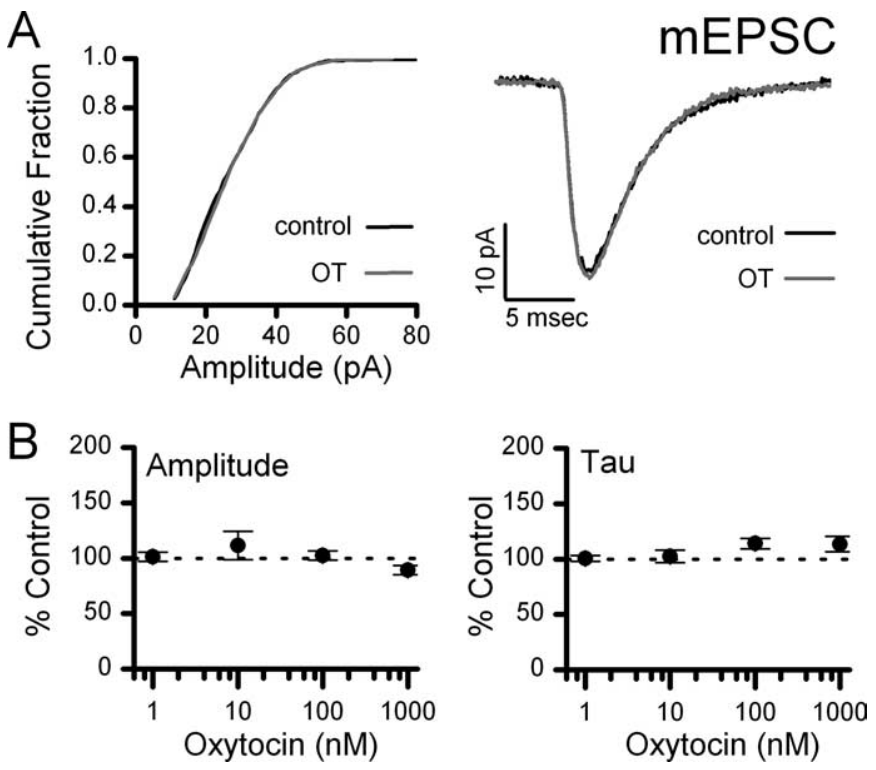

Figure 3. OT has no effect on $\mathrm{mEPSC}$ waveforms. Individual events were fit for amplitude and decay time-constant. $A$, Left, 0 T produced no change in the amplitude distribution (K-S test, $p>0.05)$. $\boldsymbol{A}$, Right, Averaged mEPSC events from an OT-sensitive NTS neuron during control and OT (1000 nM) exposure. $\boldsymbol{B}$, Normalized group averages for similarly tested OTsensitive NTS neurons across OT concentrations. OT had no significant effect on mEPSC amplitude or decay time-constant ( $n=4-8$ neurons/conc., $p>0.05$, ANOVA).

amplitude across $\geq 50$ EPSC trials was consistent (Fig. $5 A$, lower plots). The means and their associated variance for each neuron generated a $V-M$ relationship that was well fit by the parabolic model individually (Fig. $5 A$, right panel) and across neurons $\left(r^{2}\right.$ $=0.98 \pm 0.01, n=18)$. Because this $V-M$ analysis indicated that glutamate release at $2 \mathrm{mM} \mathrm{Ca}^{2+}$ was consistently near maximum in most NTS neurons, the effects of OT on evoked EPSCs were performed in $1 \mathrm{mM} \mathrm{Ca}^{2+}$ aCSF.

In $1 \mathrm{mM} \mathrm{Ca}^{2+}$, OT increased the amplitude of ST-evoked EPSCs and decreased their variance (Fig. $5 B$ ); similar responses were observed in 8 of 18 second-order NTS neurons tested. The increase in EPSC amplitude was concentration dependent and significantly different from control at $100 \mathrm{~nm}$ OT $(p<0.05$, ANOVA). OT did not change the decay kinetics of ST-EPSCs at any concentration tested ( $p>0.05$, ANOVA) (Fig. $5 B$, right panel). To facilitate comparisons across neurons (Fig. $5 C$ ), $V-M$ relationships were normalized by dividing $V$ and $M$ by the maximum EPSC (EPSC ${ }_{\max }$ ) estimated from the parabolic fit within individual neurons (Fig. 5A, right panel). Across medial NTS second-order neurons, the averaged quantal size $(q)$ was $24.42 \pm$ $3.27 \mathrm{pA}$, and the number of release sites $(N)$ was calculated to be $12.66 \pm 2.55$ sites. The mean properties for the $V-M$ relationships for OT-sensitive second-order neurons overlapped with the properties for $V-M$ relationships of OT-resistant second-order neurons (Fig. 5C, left panel). The similarity between these two groups of second-order NTS neurons as well as with results of other studies (Bailey et al., 2006) reinforces the view that STafferent glutamate release properties are remarkably similar across medial NTS second-order neurons.

Our mEPSC results suggested that OT acted presynaptically to increase the probability of glutamate release. When plotted as a $V-M$ relationship, increases in $P_{\mathrm{R}}$ predict that, at constant ionic conditions, the EPSC amplitude and its variance will follow a parabolic relationship (Clements and Silver, 2000; Clements, 2003). Plots of the mean $V-M$ values for OT-sensitive neurons in
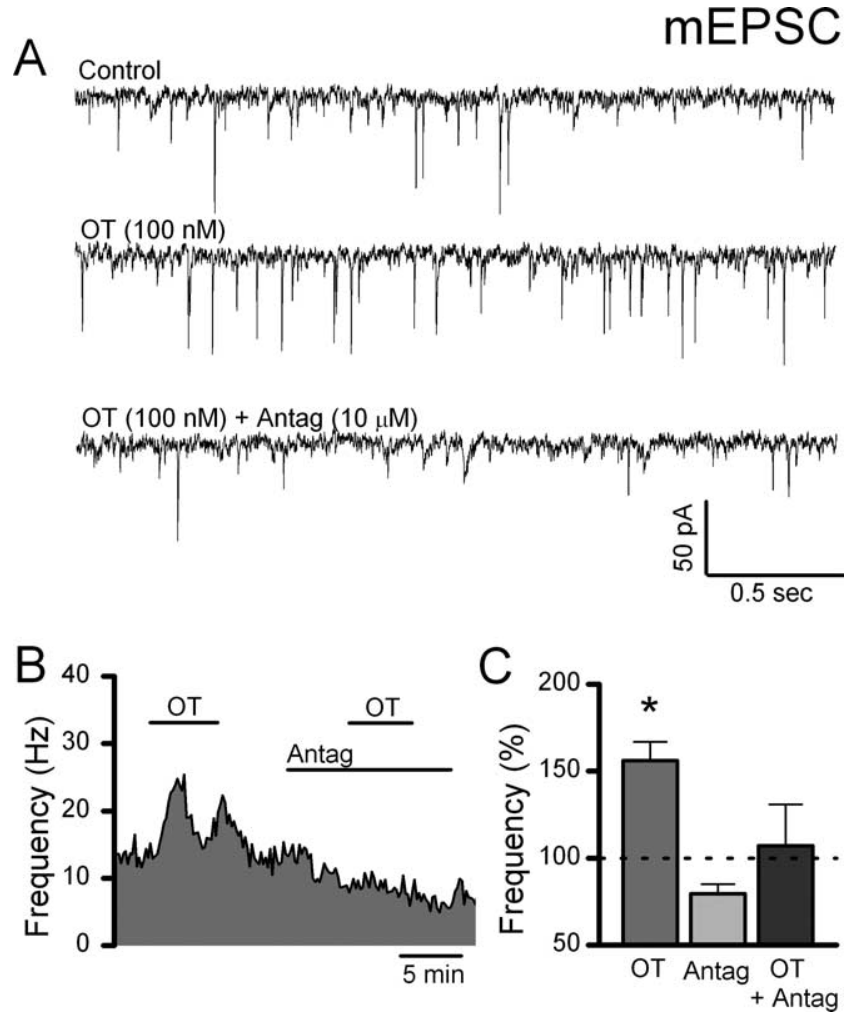

Figure 4. The competitive $0 \mathrm{~T}$-receptor antagonist $\left(\left[\mathrm{D}\left(\mathrm{CH}_{2}\right)_{5}{ }_{5}{ }^{1}, \mathrm{Tyr}(\mathrm{Me})^{2}, \mathrm{Thr}^{4}, \mathrm{Orn}^{8}\right.\right.$, des-Gly$\mathrm{NH}_{2}{ }^{9}$ ]-vasotocin) attenuates the OT-induced increase in mEPSC frequency. TTX and GZ were present throughout to isolate mEPSCs. $A$, Representative current traces show that $0 \mathrm{~T}(100 \mathrm{nM})$ increased the mEPSC frequency. The competitive oxytocin receptor antagonist was applied at 100 -fold excess and blocked the effect of OT. $\boldsymbol{B}$, In an OT-sensitive NTS neuron, exposure to the OT-receptor antagonist blocked the $0 T$-induced increase in mEPSC frequency. Frequency data were grouped into $10 \mathrm{~s}$ bins and plotted over time. $C$, Normalized group data across similarly treated 0T-sensitive NTS neurons under each condition. OT ( $100 \mathrm{~nm})$ increased the frequency of isolated $\mathrm{mEPSCS}\left({ }^{*} p>0.05\right)$. The presence of the 0 T receptor antagonist $(10 \mu \mathrm{m})$ alone did not significantly change mEPSC frequency; however, coapplication with $0 \mathrm{~T}(100 \mathrm{nM})$ attenuated the $0 T$-induced increase in frequency. These results indicate that $0 \mathrm{~T}$ acts specifically via $0 \mathrm{~T}$ receptors to increase glutamate release onto $\mathrm{OT}$-sensitive second-order NTS neurons.

$1 \mathrm{mM} \mathrm{Ca}^{2+}$ show that different concentrations of OT yielded $V-M$ values that closely followed the mean parabolic relationship along the predicted parabolic fit (Fig. $5 C$, right panel). Thus, from a mean $P_{\mathrm{R}}$ of $0.63 \pm 0.02, P_{\mathrm{R}}$ increased to $0.73 \pm 0.03$ and $0.84 \pm$ 0.05 at 100 and $1000 \mathrm{~nm} \mathrm{OT}$, respectively. In addition, OT selectively increased the $P_{\mathrm{R}}$ at the presynaptic terminal without altering either $q$ or $N$. The latency to ST-EPSC onset reflects the presynaptic properties and structures along the conduction pathway which contribute to the ST afferent conduction velocity. STEPSC latency did not change during OT exposure in OT-sensitive neurons (control: $4.85 \pm 0.56 \mathrm{~ms}$ vs $4.82 \pm 0.57 \mathrm{~ms}, p>0.41, n=$ 8 ); a finding that suggests that OT does not affect action potential propagation.

Although we have studied both mEPSCs and evoked EPSCs, the release process in these two paradigms differs by the prominent participation of voltage-dependent mechanisms in the evoked case. To compare evoked and spontaneous release in the same neurons, we recorded the frequencies of spontaneous EPSCs (sEPSCs) after each recorded evoked ST-EPSC (see protocol diagram, Fig. 6A). OT significantly facilitated both evoked STEPSC amplitudes as well as sEPSCs in every OT-sensitive NTS neuron $(n=8)$ with a similar time course (Fig. 6). In OTresistant neurons, sEPSCs were unchanged $(p>0.05, n=10$, 
results not shown). Thus across all protocols (OT-sensitive: 27 of 53 neurons tested), OT augments both evoked and spontaneous release of glutamate on OTsensitive second-order NTS neurons through what appears to be a common mechanism.

\section{OT-sensitive tonic holding current}

In addition to its synaptic actions, OT produced an increased inward current from control at constant holding potential in OT-sensitive second-order NTS neurons (Fig. 7A). The mean change in holding current was concentration dependent with an $\mathrm{EC}_{50}=\sim 30 \mathrm{~nm} \mathrm{OT}(n=13)$ (Fig. $\left.7 B\right)$. In a subset of OT-sensitive neurons $(n=$ 4 ), command voltage ramps $(-105 \mathrm{mV}$ to $-55 \mathrm{mV}$ ) were performed during control and OT (1000 nm) exposure (Fig. 7C, top panel). The subtracted, OT-sensitive current was associated with a significant decrease in slope conductance (control: $1.31 \pm 0.22 \mathrm{pA} / \mathrm{mV}$ vs OT: $1.11 \pm 0.24$ $\mathrm{pA} / \mathrm{mV}, n=4, p<0.05)$ and reversed at $-95.15 \pm 1.80 \mathrm{mV}$ that was near the calculated $\mathrm{K}^{+}$equilibrium potential $(-90.5$ $\mathrm{mV}$ ) (Fig. 7C). Even at the highest concentrations of OT tested, the magnitude of the tonic current was small relative to the total holding current and did not measurably change the kinetic properties of the EPSCs. In OT-resistant second-order NTS neurons, OT did not alter the holding current level $(p>0.05)$. Thus, the OT-sensitive $\mathrm{K}^{+}$selective conductance was found only in neurons bearing OT-sensitive glutamatergic synaptic terminals.

\section{NTS neurons receive close appositions from oxytocin-containing axons}

In brainstem sections, varicose OTimmunoreactive axons were widely dispersed across the caudal NTS at moderate densities of innervation (Fig. $8 A$ ). The majority of OT-immunoreactive axons were fine with small varicosities, although occasional OT containing axons were thick with large varicosities. At the ultrastructural level, OT-immunoreactive axon terminals that contained both small round and large granular vesicles formed synapses on NTS dendrites (Fig. 8 B). In juxtacellular labeling experiments, a total of 10 NTS neurons from six rats fired action potentials in response to electrical stimulation of the vagus and to activation of cardiopulmonary afferents with right atrial injection of phenylbiguanide. The juxtacellularly labeled neurons were distributed over a broad region of the NTS. Their cell bodies (Fig. $8 C$ ) were found from the calamus scriptorus to the rostral border of the area postrema, from the dorsal to the ventral aspect of the NTS and from just lateral to the midline to the lateral boundary of the NTS. Half of the juxtacellularly labeled NTS neurons (5 of 10), received close appositions from OT-immunoreactive terminals (Fig. 8D).

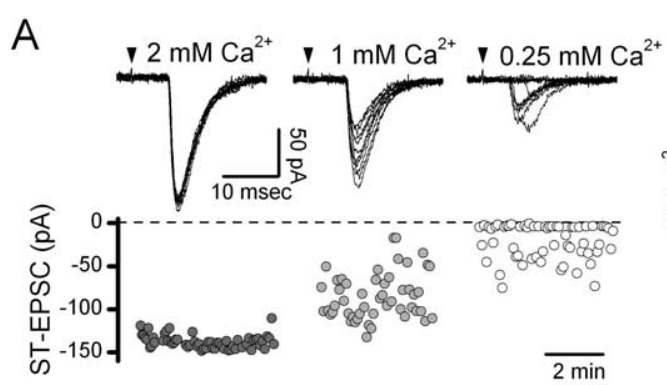

ST-EPSC
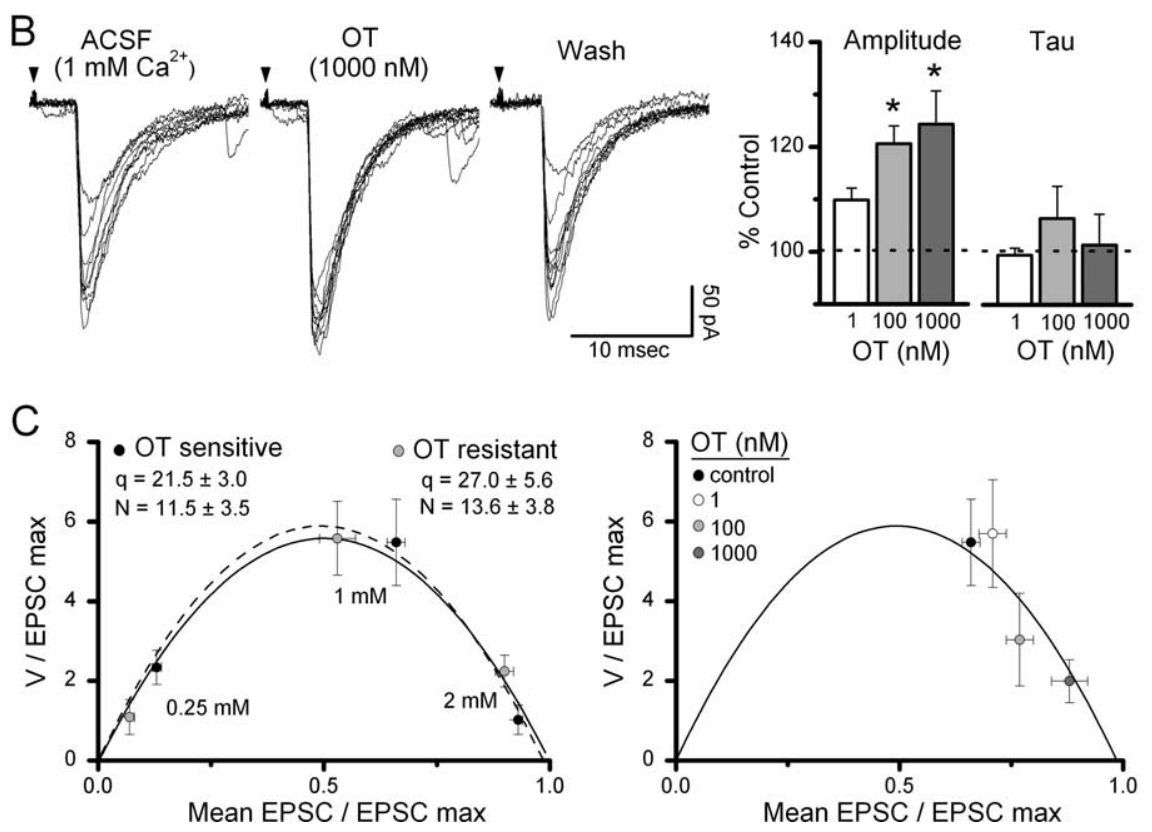

Figure 5. Variance-mean analysis of ST-NTS transmission to assess sites of OT action. $\boldsymbol{A}$, Reductions in external $\mathrm{Ca}^{2+}$ in a single representative second-order NTS neuron reduced the amplitude of ST-EPSCS and increased the variability. In the top left panel, current traces of ST-EPSC s over 10 consecutive trials are overlaid in each $\mathrm{Ca}^{2+}$ condition. Arrows indicate timing of ST shock. Scatter plot of amplitudes ( $\boldsymbol{A}$, bottom left panel) shows the steady state profiles of ST-EPSC amplitudes in each condition. In $\boldsymbol{A}$ (right panel), the mean values of this representative neuron for $V$ and $M$ associated with the three conditions were well fit by a parabolic fit (solid line, $r^{2}=0.99$ ) and indicate that $P_{\mathrm{R}}$ was 0.97 at $2 \mathrm{~mm} \mathrm{Ca}{ }^{2+}$. Because the probability of glutamate release was near maximal at $2 \mathrm{~mm} \mathrm{Ca}^{2+}$, testing of OT on ST-EPSCs was performed at $1 \mathrm{~mm}$ bath $\mathrm{Ca}^{2+}$, which averaged $P_{\mathrm{R}}=0.63 \pm 0.02$ $(n=8)$. $\boldsymbol{B}$, OT increased ST-EPSC amplitudes and decreased amplitude variability. $\boldsymbol{B}$, Left, Representative current traces (10 consecutive trials overlaid) from an 0T-sensitive NTS neuron before (ACSF, $1 \mathrm{~mm} \mathrm{Ca}{ }^{2+}$ ), during (0T, $1000 \mathrm{nm)}$ ), and after 0T exposure (wash). $\boldsymbol{B}$, Right, Across sensitive neurons, OT concentration dependently increased the average ST-EPSC amplitude with no effect on the decay time constant, tau. All values were normalized to Control $(n=8)$. *Significant differences compared with control ( $\left.{ }^{*} p<0.05\right)$. C, Left, For comparison across neurons, $V$ and $M$ values from each neuron were normalized by dividing each value by the predicted maximum EPSC amplitude EPSC $C_{\max }$ (at $p=1$, see $V-M$ relationship in $\boldsymbol{A}$, right panel). Normalized release curves were not significantly different between OT-sensitive $(n=8)$ and OT-resistant $(n=10)$ neurons $(p>0.05)$, indicating similar release mechanisms across second-order neurons in medial NTS. C (right), Addition of OT concentration-dependently increased the $P_{\mathrm{R}}$ from control under constant ionic conditions $\left(1 \mathrm{~mm} C \mathrm{a}^{2+}\right)$ along the parabolic $V-M$ relationship indicating a selective increase in the probability of glutamate release.

Closely opposing OT-positive boutons were found on both somata and dendrites of filled neurons. Even within a single, physiologically characterized group of afferent-activated NTS neurons (cardiopulmonary activated neurons), contacts by OT afferent processes selectively innervated a subset of neurons.

\section{Discussion}

OT-synthesizing PVN neurons send neuropeptide-containing axons to the caudal brainstem as part of reciprocal circuits between PVN and NTS. The medial subnucleus of NTS is a target for OT modulation of homeostatic reflexes in the context of integrating a broad array of behaviors, including those related to 

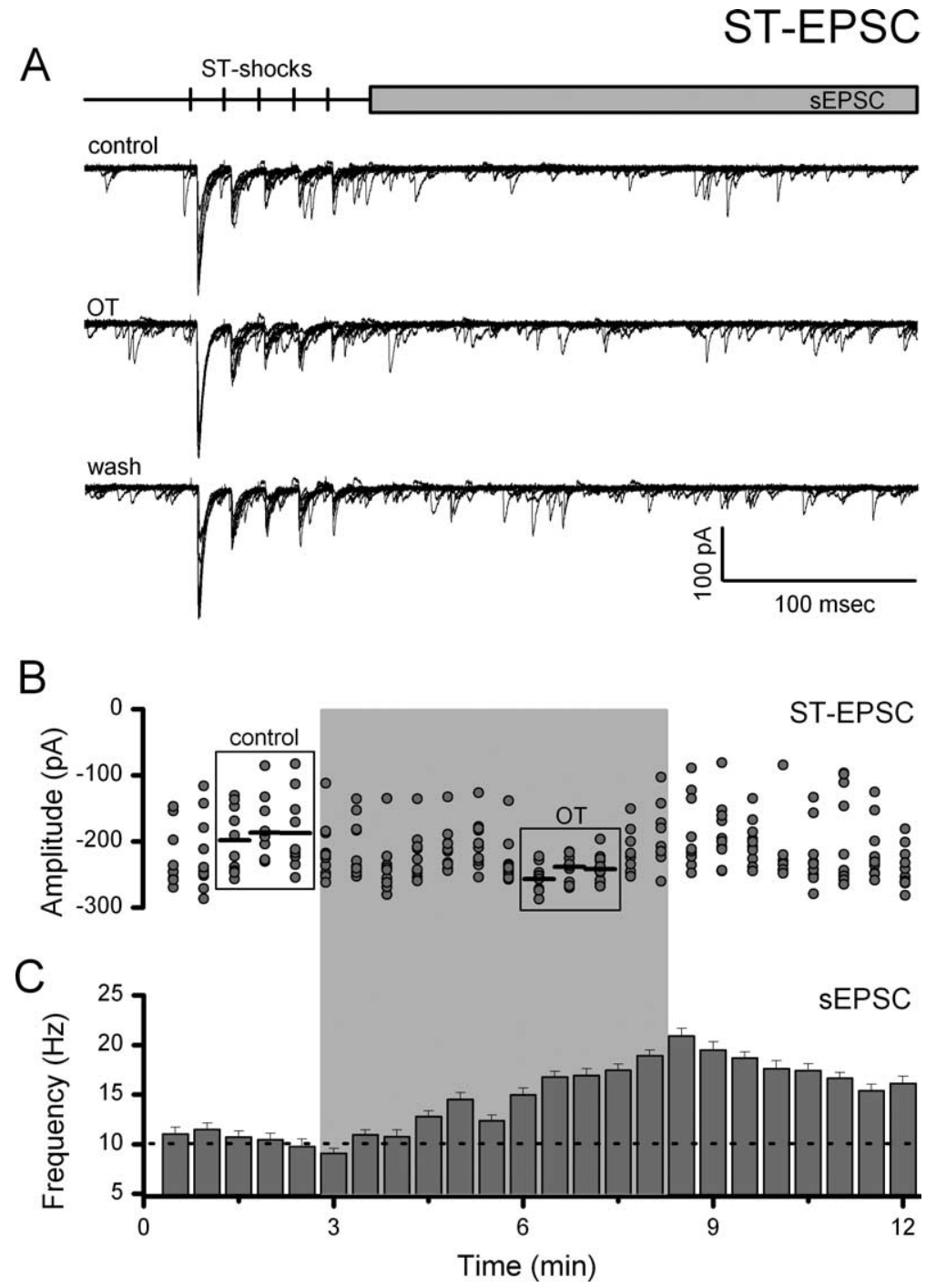

Figure 6. OT increases ST-EPSC amplitude and decreases amplitude variability coincident with increased spontaneous EPSC frequency. $\boldsymbol{A}$, Representative current traces (10 consecutive traces overlaid) from an 0T-sensitive NTS neuron before (control), during (OT, $1000 \mathrm{~nm}$ ), and after (wash) 0T exposure. Experiments were performed in $1 \mathrm{~mm} \mathrm{Ca}{ }^{2+}$ ACSF. Top panel, Diagram of recording protocol. $\boldsymbol{B}$, Plot of individual EPSC 1 amplitudes over time. Gray shading indicates time of OT exposure. OT rapidly and reversibly increased the mean amplitude of ST-EPSCS and decreased variability in OT-sensitive NTS neurons. Comparisons were made between control and peak OT responses (boxes). Horizontal black lines represent average EPSC amplitude. The SE bars have been removed for clarity. $C$, sEPSCs recorded simultaneously increased in frequency during OT exposure. Frequency data were grouped into $30 \mathrm{~s}$ bins and plotted over time. The dotted line represents the average control frequency. The effects of OT on both evoked and spontaneous glutamate release indicate a common presynaptic pathway through which the probability of glutamate release is increased.

feeding, exercise, and cardiovascular function (White et al., 1984; Braga et al., 2000; Higa et al., 2002). The distributions of OT and presumably its receptors within NTS closely parallel the distribution of visceral afferent terminals associated with such reflexes (Loewy, 1990; Blevins et al., 2003; Martins et al., 2005; Meddle et al., 2007). Here, we provide evidence that OT facilitates excitation of approximately half of the second-order neurons within medial NTS. OT selectively increases the frequency of mEPSCs on OT-sensitive neurons. $V-M$ analysis of evoked ST-EPSCs in OT-sensitive neurons indicates that activation of OT receptors selectively facilitates the probability of glutamate release at ST presynaptic terminals. A second mechanism of excitation in OTsensitive neurons increases neuronal excitability by inhibition of $\mathrm{a} \mathrm{K}^{+}$conductance. Analysis of a specific subset of NTS neurons, those activated by cardiopulmonary afferents in vivo, revealed that half received close appositions from OT immunoreactive axons and EM localized OT to synaptic terminals within NTS. Together, our findings suggest that OT enhances ST-NTS neurotransmission to a subset of second-order NTS via discrete presynaptic and postsynaptic mechanisms.

\section{OT facilitates ST transmission: presynaptic glutamate release} ST afferent transmission within the NTS is mediated via glutamate acting predominantly at postsynaptic non-NMDA receptors (Andresen and Yang, 1990; Jin et al., 2003). The glutamate release process from ST afferent terminals is remarkably uniform across second-order neurons within the medial subnucleus and displays a relatively high $\mathrm{Ca}^{2+}$ sensitivity with nearly full release at $2 \mathrm{~mm}$ (Bailey et al., 2006) whereas near maximal release at many synapses requires much higher $\mathrm{Ca}^{2+}$ (generally >3.8 mM) (Allen and Stevens, 1994; Debanne et al., 1996; Silver et al., 1998). Although many in vitro experiments are performed at elevated external $\mathrm{Ca}^{2+}$, this condition may limit the facilitation of glutamate release. At $1 \mathrm{mM} \mathrm{Ca}^{2+}$, near physiological levels, OT decreased mean amplitude and increased amplitude variance. OT-enhanced ST-EPSCs closely adhered to the parabolic $V-M$ relationship, suggesting that a selective increase in the release probability was responsible. Interestingly, the $V-M$ relations for ST-EPSCs were not significantly different between OT-sensitive and OT-resistant neurons and yielded similar estimates of $q$ and $N$ between the two groups. OT actions in NTS were highly selective and were prevented by specific antagonism of OT receptors. Our estimates of $\mathrm{EC}_{50}$ were in the low nanomolar range and indicate a high ligand-receptor affinity consistent with binding studies (Gimpl and Fahrenholz, 2001). Because OT facilitated glutamate transmission measured as mEPSCs in the presence of TTX, this OT action was independent of action potentials and may reflect a direct action on the release machinery, as in spinal cord afferent transmission (Breton et al., 2008). OT receptors can couple functionally through the $\mathrm{G}_{\mathrm{q}}$ class of GTP-binding proteins and stimulate phospholipase $\mathrm{C}$ (Gimpl and Fahrenholz, 2001). Activation of these pathways increases inositol trisphosphate and 1,2-diacyl-glycerol, which may alter internal $\mathrm{Ca}^{2+}$ stores and phosphorylation via protein kinase C (Gimpl and Fahrenholz, 2001). OT actions on glutamatergic transmission were selectively presynaptic because postsynaptic event properties (quantal amplitudes and decay time constants) were unaltered. The lack of any of these responses in OT-resistant second-order neurons despite the close proximity of OTsensitive neurons suggests a high degree of targeting and heterogeneous distribution of OT receptors. OT receptors exist on many neurons that are not contacted by cranial visceral afferents 

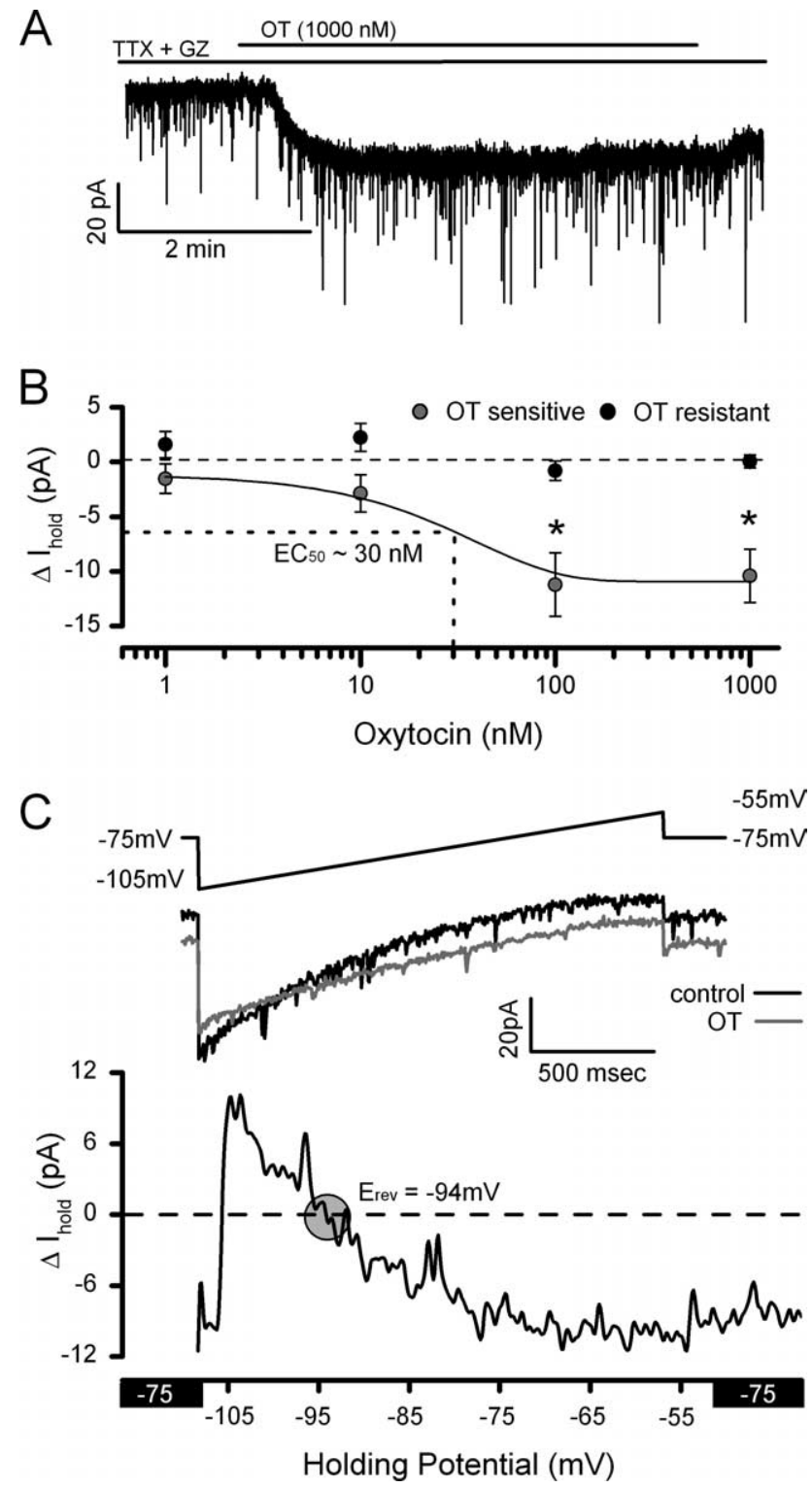

Figure 7. OT increases an inward current postsynaptically. $\boldsymbol{A}$, Representative current trace showing an 0T-evoked inward current at a constant holding potential $\left(V_{H}=-75 \mathrm{mV}\right)$ in an $0 \mathrm{~T}$-sensitive neuron. Note that numerous downward inflections in the current traces represent spontaneous EPSCS. $\boldsymbol{B}$, The $0 \mathrm{~T}$-induced mean inward current was concentration dependent and significantly different from control at $100 \mathrm{~nm} 0 \mathrm{~T}$ ( $n=4-8$ neurons/conc., $p<0.05$, ANOVA). Data are expressed as the mean \pm SEM for each concentration. $C$, To better characterize the ionic basis of the $0 T$-induced current, a depolarizing ramp protocol ( $-105 \mathrm{mV}$ to $-55 \mathrm{mV}$, top panel) was performed before (black trace) and during 0T (gray trace) exposure. OT consistently increased the input resistance only in $0 \mathrm{~T}$-sensitive NTS neurons (control: $1.31 \pm 0.22 \mathrm{pA} / \mathrm{mV}$ vs 0T: $1.11 \pm 0.24 \mathrm{pA} / \mathrm{mV}, n=4, p<0.05$ ). The difference curve (bottom panel) reverses near the $\mathrm{K}^{+}$equilibrium potential $(-90.5 \mathrm{mV})$. In addition to presynaptic targets, $0 \mathrm{~T}$ acts postsynaptically to close $\mathrm{K}^{+}$channels and produce an inward current.

such as adjacent DMN (Barberis and Tribollet, 1996). Because some DMN neurons send dendrites into medial NTS (Zhang et al., 1998), these anatomical overlaps across the histological boundaries are challenging to distinguish by OT staining alone and raise the confounding possibility that some staining sites within medial NTS might belong to DMN dendritic OT expression. Our functional studies are consistent with a presence of OT receptors in ST afferents as well as postsynaptically on medial NTS neurons.
OT mechanisms contrast with vasopressin in medial NTS

Both OT and the PVN-associated neuropeptide, vasopressin, are present within medial NTS. Vasopressin structurally resembles OT and differs only by 2 aa. Vasopressin decreased $P_{\mathrm{R}}$ for glutamate from ST terminals via V1a receptors in approximately onethird of medial NTS neurons, including those contacted by aortic baroreceptors (Bailey et al., 2006). Thus, OT regulates neurons oppositely from vasopressin within medial NTS (Michelini and Bonagamba, 1988; Dufloth et al., 1997; Braga et al., 2000; Bailey et al., 2006). In previous studies (Bailey et al., 2006), vasopressin actions in medial NTS were specifically and completely antagonized by blockade of V1a receptors with the nonapeptide, SR49059. Vasopressin-sensitive NTS neurons do not appear to coexpress OT receptors because vasopressin has significant activity at OT receptors (Hirasawa et al., 2003). Given the structural similarities, however, OT receptors possess a 100-fold higher efficacy for OT binding compared with vasopressin (Gimpl and Fahrenholz, 2001). Although OT activation of V1a receptors is possible, we did not observe synaptic inhibition, which would be expected with V1a receptor activation in NTS. These results together with our previous observations suggest that OT and V1a receptors are largely segregated to separate populations of second-order neurons within medial NTS.

\section{Nonsynaptic targets of OT}

OT had the additional effect of inhibiting a $\mathrm{K}^{+}$conductance in OT-sensitive second-order neurons. This direct action of OT on the postsynaptic neuronal membrane lead to depolarization and spiking in OT-sensitive neurons (results not included) and was not observed in OT-resistant NTS neurons. Vasopressinsensitive second-order neurons have shown no postsynaptic changes to vasopressin exposure in previous studies of medial NTS (Bailey et al., 2006). Also unlike vasopressin-sensitive NTS neurons, OT had no effect on the latency to ST-EPSC onset. ST-EPSC latency reflects, in part, axonal conduction; and the lack of action of OT contrasts with the latency increases and block of ST conduction by vasopressin in the subpopulation of vasopressin-sensitive neurons (Bailey et al., 2006). Together, the presynaptic facilitation of ST-EPSCs and the postsynaptic depolarization would facilitate excitation of OT-sensitive secondorder neurons during afferent volleys. These observations suggest that PVN OT axons modulate visceral afferent processing and enhance afferent reflex responses via presynaptic and postsynaptic mechanisms (Maley, 1996; Blevins et al., 2003).

\section{Oxytocinergic innervation of NTS}

Electrical stimulation of the PVN transiently increases OT content within the NTS and this response is blocked by transection of the PVN-NTS connection (Landgraf et al., 1990). As shown previously (Blevins et al., 2003), we found a moderate density of OT-immunoreactive axons widely dispersed throughout the caudal NTS. OT-positive fibers formed close appositions on only half of the physiologically identified NTS neurons that were activated by vagal cardiopulmonary receptors, and these appositions occurred on both dendrites and cell bodies. In ultrastructural studies, we identified OT-immunoreactivity in terminals that contained and large granular vesicles and formed asymmetric axodendritic synapses. Our structural and electrophysiological studies indicate that half of NTS neurons respond to OT and receive innervation from OT-containing axons. These differences may reflect PVN interactions with specific cohorts of second-order neurons. Even within a narrow subset of NTS neurons, those that were activated by vagal cardiopulmonary recep- 


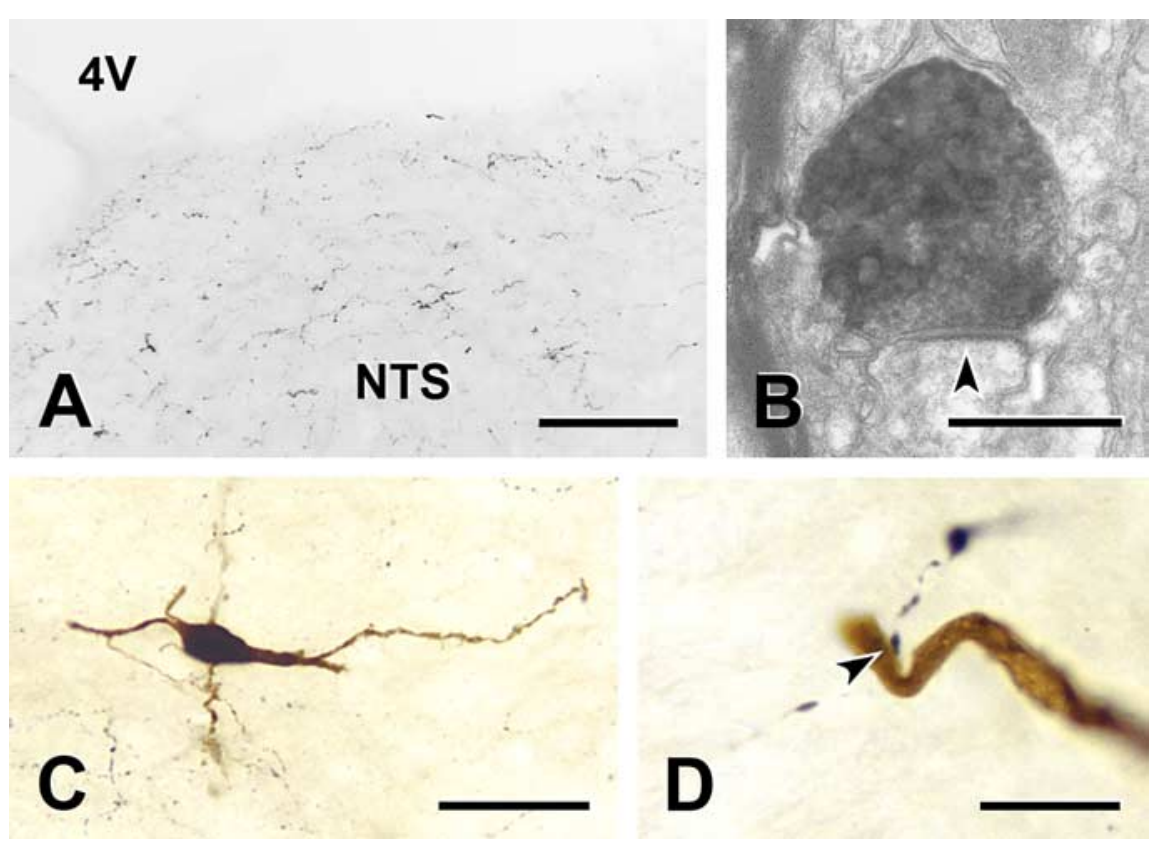

Figure 8. $\quad$ OT-containing fibers innervate NTS neurons. $\boldsymbol{A}$, Representative light micrograph illustrates 0T-immunoreactive axons within the NTS. Scale bar, $100 \mu \mathrm{m}$. Immunoreactive axons (black profiles) were small with fine varicosities and were distributed evenly throughout the NTS. $\boldsymbol{B}$, Electron micrograph showing that an OT-immunoreactive terminal containing both small round and large granular vesicles forms an asymmetric synapse (arrow) on a dendrite in the NTS. Scale bar, $500 \mathrm{~nm}$. C, NTS neuron that responded to cardiopulmonary afferent stimulation and was juxtacellularly filled with Neurobiotin (dark brown profile). Section immunostained to show OT-immunoreactive axons (black profiles). This second order neuron was spindleshaped and had dendrites that could be followed for several hundred micrometers. Scale bar, $50 \mu \mathrm{M}$. D, An 0T-immunoreactive terminal forms a close apposition (arrow) on the dendrite of the neuron whose cell body is shown in C. Scale bar, $10 \mu \mathrm{m}$. OT-immunoreactive terminals formed close appositions with 5 of 10 filled NTS neurons.

tors, OT containing fibers contacted some neurons and not others. This nonuniformity in OT-responsiveness and innervation of NTS neurons supports observations on NTS neurons physiologically characterized in vivo (McCann and Rogers, 1990). Because the mechanisms of OT action across OT-sensitive neurons were similar, our data suggest that the heterogeneous innervation may confer the specificity that we found in the physiological actions of OT. Both OT and vasopressin are linked to cardiopulmonary and arterial baroreceptive vagal afferents that provide integrative regulation of cardiovascular, body fluid and electrolyte homeostasis (Cunningham et al., 2002). Together with what is known about vasopressin actions in NTS, our findings and others suggest that OT and vasopressin released by PVN axons in the NTS provide functionally opposite controls that may act at different neuronal cell groups (Raggenbass, 2008). These converse actions of OT and vasopressin on cranial visceral afferent neurotransmission may underlie coordinated hypothalamus-brainstem interactions during complex behaviors as part of both acute and chronic adaptive coordination of visceral function ( $\mathrm{Li}$ et al., 1997; Martins et al., 2005).

\section{Conclusions}

OT enhances ST-NTS neurotransmission by presynaptically increasing glutamate release from ST afferent terminals and postsynaptic production of an inward current that should lead to heightened excitability by depolarization. Oxytocinergic fibers from the PVN selectively innervate the NTS, forming close appositions with only a subpopulation of neurons. These findings demonstrate the cellular mechanisms underlying OT effects on glutamatergic neurotransmission within the NTS; which are likely to participate in key PVN-orchestrated changes in auto- nomic function to best match a wide range of complex behaviors such as feeding, exercise, and stress.

\section{References}

Allen C, Stevens CF (1994) An evaluation of causes for unreliability of synaptic transmission. Proc Natl Acad Sci US A 91:10380-10383.

Andresen MC, Kunze DL (1994) Nucleus tractus solitarius: gateway to neural circulatory control. Annu Rev Physiol 56:93-116.

Andresen MC, Yang MY (1990) Non-NMDA receptors mediate sensory afferent synaptic transmission in medial nucleus tractus solitarius. Am J Physiol 259:H1307-H1311.

Bailey TW, Jin Y-H, Doyle MW, Smith SM, Andresen MC (2006) Vasopressin inhibits glutamate release via two distinct modes in the brainstem. J Neurosci 26:6131-6142.

Barberis C, Tribollet E (1996) Vasopressin and oxytocin receptors in the central nervous system. Crit Rev Neurobiol 10:119-154.

Blevins JE, Eakin TJ, Murphy JA, Schwartz MW, Baskin DG (2003) Oxytocin innervation of caudal brainstem nuclei activated by cholecystokinin. Brain Res 993:30-41.

Braga DC, Mori E, Higa KT, Morris M, Michelini LC (2000) Central oxytocin modulates exercise-induced tachycardia. Am J Physiol Regul Integr Comp Physiol 278:R1474-R1482.

Breton JD, Veinante P, Uhl-Bronner S, Vergnano AM, Freund-Mercier MJ, Schlichter R, Poisbeau P (2008) Oxytocin-induced antinociception in the spinal cord is mediated by a subpopulation of glutamatergic neurons in laminas I-II which amplify GABAergic inhibi-

tion. Mol Pain 4:19.

Clements JD (2003) Variance-mean analysis: a simple and reliable approach for investigating synaptic transmission and modulation. J Neurosci Methods 130:115-125.

Clements JD, Silver RA (2000) Unveiling synaptic plasticity: a new graphical and analytical approach. Trends Neurosci 23:105-113.

Cunningham JT, Bruno SB, Grindstaff RR, Grindstaff RJ, Higgs KH, Mazzella D, Sullivan MJ (2002) Cardiovascular regulation of supraoptic vasopressin neurons. Prog Brain Res 139:257-273.

Debanne D, Guérineau NC, Gähwiler BH, Thompson SM (1996) Pairedpulse facilitation and depression at unitary synapses in rat hippocampus: quantal fluctuation affects subsequent release. J Physiol 491:163-176.

Doyle MW, Andresen MC (2001) Reliability of monosynaptic transmission in brain stem neurons in vitro. J Neurophysiol 85:2213-2223.

Doyle MW, Bailey TW, Jin YH, Appleyard SM, Low MJ, Andresen MC (2004) Strategies for cellular identification in nucleus tractus solitarius slices. J Neurosci Methods 137:37-48.

Dubois-Dauphin M, Raggenbass M, Widmer H, Tribollet E, Dreifuss JJ (1992) Morphological and electrophysiological evidence for postsynaptic localization of functional oxytocin receptors in the rat dorsal motor nucleus of the vagus nerve. Brain Res 575:124-131.

Dufloth DL, Morris M, Michelini LC (1997) Modulation of exercise tachycardia by vasopressin in the nucleus tractus solitarii. Am J Physiol 273:R1271-R1282.

Flanagan LM, Olson BR, Sved AF, Verbalis JG, Stricker EM (1992) Gastric motility in conscious rats given oxytocin and an oxytocin antagonist centrally. Brain Res 578:256-260.

Gimpl G, Fahrenholz F (2001) The oxytocin receptor system: structure, function, and regulation. Physiol Rev 81:629-683.

Henry JL, Sessle BJ (1989) Vasopressin and oxytocin express excitatory effects on respiratory and respiration-related neurones in the nuclei of the tractus solitarius in the cat. Brain Res 491:150-155.

Higa KT, Mori E, Viana FF, Morris M, Michelini LC (2002) Baroreflex control of heart rate by oxytocin in the solitary-vagal complex. Am J Physiol Regul Integr Comp Physiol 282:R537-R545. 
Hirasawa M, Mouginot D, Kozoriz MG, Kombian SB, Pittman QJ (2003) Vasopressin differentially modulates non-NMDA receptors in vasopressin and oxytocin neurons in the supraoptic nucleus. J Neurosci 23:4270-4277.

Jeggo RD, Kellett DO, Wang Y, Ramage AG, Jordan D (2005) The role of central 5-HT3 receptors in vagal reflex inputs to neurones in the nucleus tractus solitarius of anaesthetized rats. J Physiol 566:939-953.

Jin YH, Bailey TW, Doyle MW, Li BY, Chang KSK, Schild JH, Mendelowitz D, Andresen MC (2003) Ketamine differentially blocks sensory afferent synaptic transmission in medial nucleus tractus solitarius (mNTS). Anesthesiology 98:121-132.

Jones GA, Llewellyn-Smith IJ, Jordan D (2002) Physiological, pharmacological, and immunohistochemical characterisation of juxtacellularly labelled neurones in rat nucleus tractus solitarius. Auton Neurosci 98:12-16.

Kay IS, Armstrong DJ (1990) Phenylbiguanide not phenyldiguanide is used to evoke the pulmonary chemoreflex in anaesthetized rabbits. Exp Physiol 75:383-389.

Landgraf R, Malkinson T, Horn T, Veale WL, Lederis K, Pittman QJ (1990) Release of vasopressin and oxytocin by paraventricular stimulation in rats. Am J Physiol 258:R155-R159.

Li J, Hand GA, Potts JT, Mitchell JH (1997) Identification of hypothalamic vasopressin and oxytocin neurons activated during the exercise pressor reflex in cats. Brain Res 752:45-51.

Llewellyn-Smith IJ, Minson JB (1992) Complete penetration of antibodies into vibratome sections after glutaraldehyde fixation and ethanol treatment: light and electron microscopy for neuropeptides. J Histochem Cytochem 40:1741-1749.

Llewellyn-Smith IJ, DiCarlo SE, Collins HL, Keast JR (2005) Enkephalinimmunoreactive interneurons extensively innervate sympathetic preganglionic neurons regulating the pelvic viscera. J Comp Neurol 488:278-289.

Loewy AD (1990) Central autonomic pathways. In: Central regulation of autonomic functions (Loewy AD, Spyer KM, eds), pp 88-103. New York: Oxford.

Maley BE (1996) Immunohistochemical localization of neuropeptides and neurotransmitters in the nucleus solitarius. Chem Senses 21:367-376.

Martins AS, Crescenzi A, Stern JE, Bordin S, Michelini LC (2005) Hypertension and exercise training differentially affect oxytocin and oxytocin receptor expression in the brain. Hypertension 46:1004-1009.
McCann MJ, Rogers RC (1990) Oxytocin excites gastric-related neurones in rat dorsal vagal complex. J Physiol 428:95-108.

Meddle SL, Bishop VR, Gkoumassi E, van Leeuwen FW, Douglas AJ (2007) Dynamic changes in oxytocin receptor expression and activation at parturition in the rat brain. Endocrinology 148:5095-5104.

Michelini LC (2007) Differential effects of vasopressinergic and oxytocinergic pre-autonomic neurons on circulatory control: reflex mechanisms and changes during exercise. Clin Exp Pharmacol Physiol 34:369-376.

Michelini LC, Bonagamba LGH (1988) Baroreceptor reflex modulation by vasopressin microinjected into the nucleus tractus solitarii of conscious rats. Hypertension 11:I75-I79.

Raggenbass M (2008) Overview of cellular electrophysiological actions of vasopressin. Eur J Pharmacol 583:243-254.

Raggenbass M, Dubois-Dauphin M, Charpak S, Dreifuss JJ (1987) Neurons in the dorsal motor nucleus of the vagus nerve are excited by oxytocin in the rat but not in the guinea pig. Proc Natl Acad Sci U S A 84:3926-3930.

Raggenbass M, Tribollet E, Dubois-Dauphin M, Dreifuss JJ (1989) Vasopressin receptors of the vasopressor (V1) type in the nucleus of the solitary tract of the rat mediate direct neuronal excitation. J Neurosci 9:3929-3936.

Saper CB (2002) The central autonomic nervous system: conscious visceral perception and autonomic pattern generation. Annu Rev Neurosci 25:433-469.

Sawchenko PE, Swanson LW (1982) Immunohistochemical identification of neurons in the paraventricular nucleus of the hypothalamus that project to the medulla or to the spinal cord in the rat. J Comp Neurol 205:260-272.

Silver RA, Momiyama A, Cull-Candy SG (1998) Locus of frequencydependent depression identified with multiple-probability fluctuation analysis at rat climbing fibre Purkinje cell synapses. J Physiol 510:881-902.

Sofroniew MV, Schrell U (1980) Hypothalamic neurons projecting to the rat caudal medulla oblongata, examined by immunoperoxidase staining of retrogradely transported horseradish peroxidase. Neurosci Lett 19:257-263.

White JD, Krause JE, McKelvy JF (1984) In vivo biosynthesis and transport of oxytocin, vasopressin, and neurophysins to posterior pituitary and nucleus of the solitary tract. J Neurosci 4:1262-1270.

Zhang X, Renehan WE, Fogel R (1998) Neurons in the vagal complex of the rat respond to mechanical and chemical stimulation of the GI tract. Am J Physiol 274:G331-G341. 